\title{
Evaluation of the Accuracy of SRTM3 and ASTER GDEM in the Tibetan Plateau Mountain Ranges
}

\author{
Jin $\mathrm{Yao}^{1}$, Yi Chao-lu², Fu Ping ${ }^{3 *}$ \\ ${ }^{1}$ China Institute of Geo-Environment Monitoring, Beijing, China \\ ${ }^{2}$ Key Laboratory of Tibetan Environment Changes and Land Surface Processes, Institute of Tibetan Plateau Research, Chinese Academy \\ of Sciences, Beijing, China \\ ${ }^{3}$ School of Geographical Sciences, Faculty of Science and Engineering, The University of Nottingham Ningbo China, Ningbo, China
}

\begin{abstract}
Topographic data on The Tibetan Plateau (TP) terrain are fundamental for geoscientific research, but are difficult to obtain. The Shuttle Radar Topographic Mission (SRTM) Digital Elevation Model (DEM) and the Advanced Spaceborne Thermal Emission and Reflection Radiometer Global Digital Elevation Model (ASTER GDEM) are two commonly used GDEM data. Verifying the accuracy of the two dataset for the TP mountain areas provides a reference point for the application of both DEMs. For evaluating the elevation accuracy and topographic information, we used 8242 field measurements from Differential Global Positioning System (DGPS) points and DEM data generated from 1:100,000 topographic maps to examine the accuracy of ASTER GDEM V2 and SRTM3 V4.1 elevation results. The average RMSE for elevation differences between DGPS and ASTER GDEM across the study areas was $18.56 \mathrm{~m}$, while the average RMSE between DGPS and SRTM3 was 10.39m. The average RMSEs of ASTER GDEM and SRTM3 in glaciated areas were $8.55 \mathrm{~m}$ and $5.87 \mathrm{~m}$, respectively. The vertical accuracy of SRTM3 is better than that of ASTER GDEM. The vertical accuracy of both DEMs do not vary with altitude, but is related to aspect and slope.
\end{abstract}

\section{Introduction}

Digital Elevation Model (DEM) produced based on remotely sensed data provide useful terrain data sources for Earth and environmental scientific research, particularly for the remote and vast Tibetan Plateau (TP). Two free global DEMs, one from the Shuttle Radar Topographic Mission (SRTM) and another from the Advanced Spaceborne Thermal Emission and Reflection Radiometer Global Digital Elevation Model (ASTER GDEM), cover the majority of the world's populated regions. They have been widely used in geology, geomorphology, hydrology, and glaciology [1-4]. Multiple studies have evaluated the accuracy of the data produced by SRTM and ASTER GDEM [5-13]. Several data have been adopted to assess their accuracy in practical use. The elevations measured by the Global Positioning System (GPS) have commonly been used as reference data to be compared to DEMs to assess their accuracies [13-15]. Topographic maps[6,8,12], the Ice, Cloud and Land Elevation Satellite (ICEsat) data[10,16,17], geodetic ground control points[7] or Light Detection and Ranging data[9,11] have also provided such reference data for assessing the accuracy of DEM data.

The ASTER GDEM and SRTM3 DEM provide valuable terrain information for TP, which lacks high resolution topographic data due to the difficulties in access for directly field survey. Researchers have already used these DEMs to monitor glacial changes in the TP [18], to analyse earthquakes [19], to model hydrological processes [20] and glacial lake outbursts [13], and to map glacial landscapes [21]. However, most of these studies did not assess the accuracy of the data used. Although some recharges evaluated the accuracy of these two DEMs on the TP $[10,13]$, the study sites were constrained in two small areas and the sample numbers were limited for a proper assessment of the accuracy of the models over such broad area. Wan et al. and Gao et al. evaluated the accuracy of SRTM by using ICESat/GLAS data in the TP $[17,22]$, however, there is a lack of verification of the accuracy of DEM data in glacier regions and assessment of topographic information. Therefore, in this paper, we assess the accuracies of ASTER GDEM V2 and SRTM3 V4.1 data by comparing them with DGPS measurements and the DEM generated from 1:100,000 topographic maps (DEM10), with the aim of furthering the use of DEMs on the TP.

\section{Study areas}

TP is located between $74^{\circ}-104^{\circ} \mathrm{E}$ and $25^{\circ}-40^{\circ} \mathrm{N}$, with a total area of ca. $2.5 \times 106 \mathrm{~km} 2$, and an average elevation $>4000 \mathrm{~m}$ a.s.l. (above sea level). The TP consists of several extensive mountain chains separated

\footnotetext{
* Corresponding author: ping.fu@nottingham.edu.cn
} 
by vast basins and plateaus (Fig. 1), with the Himalaya in the south, the Kunlun Mountains and Qilian Mountains in the north, the Karakoram Mountains in the west, and the Hengduan Mountains in the east. These mountain ranges cover a significant area of the TP.

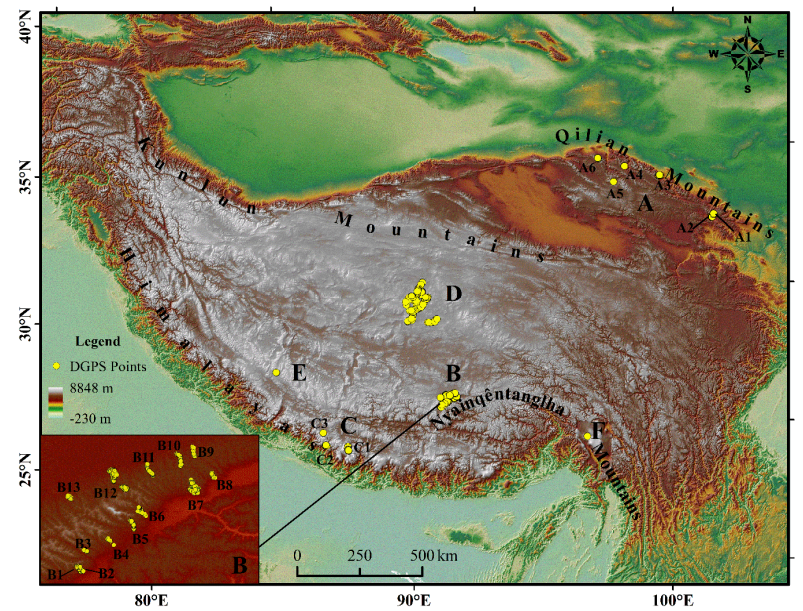

Fig. 1. Location map of the study areas. DGPS points surveyed in the field (yellow dots) are indicated on a shaded relief map. A to $\mathrm{F}$ are the study areas.

GPS elevation data were collected in six, mostly mountainous, areas (A to F) (Fig. 1). Area A is located in the Qilian Mountains in northeastern TP and contains six sites with 1492 DGPS points. One of the sites A1 is named after Laolongwan, which is located in southeastern Qilian Mountains and has diverse landforms (Fig. 7). Area $\mathrm{B}$ is located in the Nyainqêntanglha Mountains in southeastern Tibet and contains 13 sites with 3941 GPS points. One of the sites B4 is named after Yangbajing, which is located in glacial area (Fig. 5). Area $\mathrm{C}$ is in the Himalaya on the southern border of Tibet and contains three sites with 1335 GPS points. Area D is in the Puruogangri Ice Field to the east of the Qiangtang Plateau and contains one site with 1397 DGPS points. Area E is in Gila in the centre of the Kailas Range and contains 56 GPS points. Finally, Area $\mathrm{F}$ is in the valley of the Midui Glacier in the eastern Himalaya and contains 21 GPS points (Fig. 1).

\section{Data sources}

\subsection{SRTM3}

In February 2000, SRTM DEM was released by the US National Aeronautics and Space Administration (NASA) and the National Geospatial-Intelligence Agency (NGA) in order to map the world in three dimensions. It covers $>80 \%$ of the land surface of the Earth, from $60^{\circ} \mathrm{N}$ to $56^{\circ} \mathrm{S}[23]$. SRTM3 DEM (SRTM3, hereafter) data with a 3", ca. $90 \mathrm{~m}$ resolutions, are globally available. Global vertical accuracy for SRTM is $\pm 16 \mathrm{~m}$ at a $90 \%$ confidence level[24,25]. We used the latest version of the SRTM3 (ver. 4.1.) in this study.

\subsection{ASTER GDEM}

ASTER GDEM (GDEM, hereafter) is a global DEM dataset that was released in June 2009 by the Ministry of Economy, Trade and Industry of Japan (METI) and NASA. It covers $99 \%$ of the Earth's land surface from $83^{\circ} \mathrm{N}$ to $83^{\circ} \mathrm{S}$. Its horizontal resolution is ca. $30 \mathrm{~m}$ with a vertical accuracy of GDEM $\pm 20 \mathrm{~m}$ [26]. In this study, we evaluated the latest version of ASTER GDEM (ver. 2), released in October 2011.

\subsection{DEM derived from topographic maps}

The map-based DEM (DEM10, hereafter) was generated from the 1:100,000-scale topographic map which was produced on the basis of 1974 aerial photogrammetry. The topographic maps were scanned into digitized images and a contour interval of $40 \mathrm{~m}$ was applied. The digitized contours were then used to generate DEM data, also with a $40 \mathrm{~m}$ resolution, which was then projected using the Albers projection and the Krasovsky 1940 ellipsoid. DEM10 was compared to the other two DEMs to determine the accuracy of their topographic information.

\subsection{DGPS elevations}

The DGPS points were obtained by using two or more portable THALES MobileMapper units. One was used as the reference station that provided differential correction. The other(s) were used to collect DGPS points for use as mobile stations. The horizontal accuracy of the DGPS points is within $1 \mathrm{~m}$, based on the User's Manual; estimation of the vertical accuracy of the points indicated that it is within $3 \mathrm{~m}$. Since the coordinates of the base station in the field are not absolutely accurate, we evaluated the vertical accuracy of the DGPS points by using DGPS to measure the elevation at the top of Xiangshan Hill, whose altitude is known. Thus, we calculated the vertical accuracy falling within a range of $10 \mathrm{~m}$ when the coordinates of the base station were measured in field. A total of 8242 DGPS points were randomly extracted from all field measurements, the locations of which are indicated in Fig. 1. These DGPS elevation data were used to evaluate the vertical accuracies of SRTM3 and GDEM. Table 1 shows the characteristics of the four datasets for the study areas.

Table 1. The characteristics of four types of data.

\begin{tabular}{|c|c|c|c|c|}
\hline $\begin{array}{c}\text { Data } \\
\text { type }\end{array}$ & $\begin{array}{c}\text { Pixel } \\
\text { size }\end{array}$ & $\begin{array}{c}\text { Vertical } \\
\text { accuracy }\end{array}$ & Ellipsoid & $\begin{array}{c}\text { Height } \\
\text { datum }\end{array}$ \\
\hline SRTM3 & $90 \mathrm{~m}$ & $16 \mathrm{~m}$ & WGS84 & EGM96 \\
\hline $\begin{array}{c}\text { ASTER } \\
\text { GDEM }\end{array}$ & $30 \mathrm{~m}$ & $20 \mathrm{~m}$ & WGS84 & EGM96 \\
\hline DEM10 & $40 \mathrm{~m}$ & $20 \mathrm{~m}$ & Krasovsky1940 & $\begin{array}{c}\text { Yellow } \\
\text { Sea }\end{array}$ \\
\hline $\begin{array}{c}\text { DGPS } \\
\text { points }\end{array}$ & - & $10 \mathrm{~m}$ & WGS84 & $\begin{array}{c}\text { WGS84 } \\
\text { Ellipsoid }\end{array}$ \\
\hline
\end{tabular}




\section{Methods}

\subsection{Data preparation}

SRTM3 and GDEM results are presented as orthometric heights in relation to the World Geodetic System 84 (WGS84) reference system and the Earth Gravitational Model 96 (EGM96) geoid model. The DGPS elevations are referenced to the WGS84 ellipsoid and converted to orthometric heights by the EGM96 geoid model. All DEMs were projected using the WGS84. DEM10 uses the Yellow Sea Datum, which has a ca. $0.3 \mathrm{~m}$ vertical difference from the EGM96 in China [27]. This difference can be ignored since we used DEM10 only to evaluate the topographic information contained in three DEMs, and thus did not pay close attention to its height. The elevations were extracted from GDEM and SRTM3 using the same coordinates as where the DGPS elevations were measured. The elevations retrieved from GDEM and SRTM3 are referred to as GDEM and SRTM3, respectively. Shaded reliefs were generated from these DEMs in order to compare their visual effects. Slope and aspect were computed from these DEMs.

\subsection{Comparison of elevations between DEMs and DGPS}

The elevation differences between the DEMs and the DGPS were used as reference data to evaluate errors in the vertical coordinates of the two DEMs (Fig. 2 and Table 2). The following abbreviations are used hereafter: 'min.' for minimum vertical error, 'max.' for maximum vertical error, and 'mean' for mean vertical error. MAD refers to mean absolute deviation and RMSE refers to the root mean square error.

The elevation differences between the two reference data and these two DEMs were computed and are presented in Fig. 2. Their correlations with elevation, aspect and slope are analysed (Fig. 3 and 4, and Table 3). We are also interested in the performance of the two DEMs in glacier area as they are the two major topographic data for studying glaciers in the TP, so we selected a valley glacier in Yangbajing to further assess the performances of the two DEMs in glacier area (Fig. 5 and 6). Given that the diversity of geomorphic features may influence accuracy, the DGPS data from Laolongwan, which has different landforms including floodplain, ridges and valleys with gentle and steep slopes, were also selected to evaluate how landform type affects the accuracy of the DEMs (Fig. 7 and Table 4).

\subsection{Topographic information assessment}

DEM10 was used as a reference to assess the topographic information from GDEM and SRTM3 based on visual comparison and slope analysis. Hill shaded images were produced from three DEMs and then displayed two- and three-dimensionally for visual comparison (Fig. 8). Slope is an important parameter of any DEM, and higher resolution DEMs tend to show higher slope values [28]. We classified the slopes into five levels of which the distributions were counted for the three DEMs. The mean slope was also calculated in order to analyse the topographic information provided by the DEMs (Table 5).

\section{Results and discussion}

\subsection{Assessment of vertical accuracy}

\subsubsection{Assessment of vertical accuracy for GDEM and SRTM3}

Elevation differences between DGPS and the two DEMs, SRTM3 and GDEM, both display a normal distribution (Fig. 2), and most of the differences fall within $\pm 40 \mathrm{~m}$. The range of differences are smaller for SRTM3 than for GDEM. In most cases, the differences with SRTM3 are lower than those with GDEM. This implies that SRTM3 values are closer to DGPS values than are those rendered by GDEM.
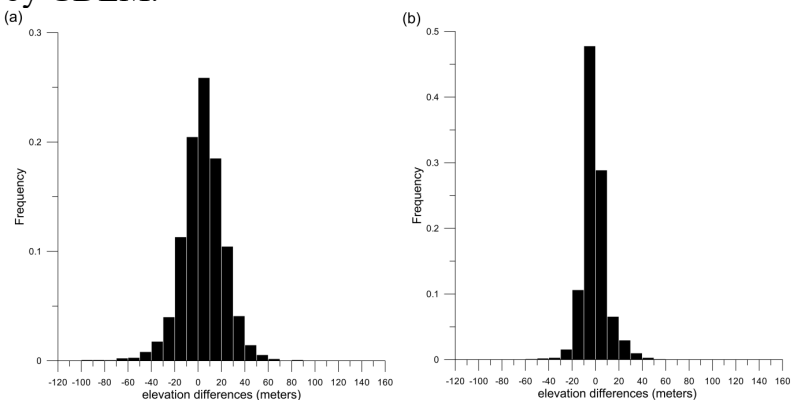

Fig. 2. Frequency distribution of elevation differences between DEMs and DGPS: (a) GDEM minus DGPS; (b) SRTM3 minus DGPS.

Five variables (count, min., max., mean and RMSE) were calculated for 25 sample sites within the six major study areas, as summarised in Table 2. The differences between GDEM and DGPS range from $-102.99 \mathrm{~m}$ to $165.73 \mathrm{~m}$, with an average value of $4.1 \mathrm{~m}$; RMSE values range from $7.65 \mathrm{~m}$ to $40.09 \mathrm{~m}$, with an average of $18.6 \mathrm{~m}$. The differences between SRTM3 and DGPS range from $-80.0 \mathrm{~m}$ to $60.6 \mathrm{~m}$, with an average of $-0.8 \mathrm{~m}$, and RMSE values range from $5.52 \mathrm{~m}$ to $33.89 \mathrm{~m}$, with an average of $10.4 \mathrm{~m}$. The greatest differences occur on valley floors and sharp moraine ridges, due to the coarse cell size of the DEM, which obscure elevation changes in areas of high relief. Therefore, the accuracies of GDEM and SRTM3 are all within the nominal accuracies of such global models $(20 \mathrm{~m}$ for the GDEM and $16 \mathrm{~m}$ for SRTM3), and SRTM3 has a higher vertical accuracy than GDEM, which is consistent with the findings of Gao et al. (2019) concerning SRTM3 and GDEM[17]. 
Table 2. Elevation differences between DGPS and ASTER GDEM and SRTM3 in the specified study areas.

\begin{tabular}{|c|c|c|c|c|c|c|c|c|c|}
\hline \multirow{2}{*}{$\begin{array}{l}\text { Study } \\
\text { area }\end{array}$} & \multirow{2}{*}{$\begin{array}{l}\text { ID(Count of } \\
\text { samples) }\end{array}$} & \multicolumn{4}{|c|}{ ASTER GDEM(m) } & \multicolumn{4}{|c|}{ SRTM3(m) } \\
\hline & & Min. & Max & Mean & RMSR & Min. & Max & Mean & RMSR \\
\hline \multirow{6}{*}{ A } & $\mathrm{A} 1(98)$ & -24.51 & 33.76 & 0.98 & 11.17 & -17.31 & 16.76 & -0.08 & 6.80 \\
\hline & A2(379) & -35.14 & 58.76 & 3.61 & 13.37 & -26.46 & 26.76 & 2.20 & 7.43 \\
\hline & A3(132) & -32.05 & 58.18 & 15.14 & 18.72 & -23.05 & 60.18 & 23.48 & 25.30 \\
\hline & A4(41) & 9.76 & 46.10 & 24.30 & 25.53 & -8.21 & 29.23 & 11.25 & 13.82 \\
\hline & A5(67) & 9.69 & 64.48 & 38.07 & 39.97 & 5.67 & 42.48 & 23.28 & 24.28 \\
\hline & A6(190) & -76.05 & 26.81 & -4.60 & 14.48 & -80.05 & 16.85 & -7.38 & 14.32 \\
\hline \multirow{13}{*}{ B } & $\mathrm{B} 1(268)$ & -35.32 & 40.56 & 5.74 & 14.90 & -48.85 & 22.95 & -4.05 & 10.01 \\
\hline & B2(149) & -14.14 & 66.67 & 18.07 & 23.02 & -18.29 & 40.28 & 2.72 & 9.16 \\
\hline & B3(47) & -16.34 & 22.65 & -1.43 & 8.55 & -16.42 & 6.74 & -1.39 & 5.87 \\
\hline & B4(38) & 16.84 & 56.66 & 38.96 & 40.09 & 16.16 & 48.66 & 32.89 & 33.89 \\
\hline & B5(214) & -29.22 & 59.75 & 15.86 & 22.90 & -24.69 & 26.11 & -5.25 & 9.28 \\
\hline & B6(335) & -56.31 & 56.29 & 15.09 & 21.91 & -25.26 & 28.03 & -1.76 & 8.39 \\
\hline & B7(899) & -67.04 & 51.24 & -5.32 & 15.26 & -31.62 & 24.28 & -1.41 & 6.91 \\
\hline & B8(97) & -39.01 & 94.34 & 15.57 & 28.19 & -36.01 & 25.82 & -9.91 & 13.50 \\
\hline & B9(192) & -35.58 & 49.39 & 2.43 & 14.55 & -21.27 & 14.96 & -3.46 & 7.95 \\
\hline & B10(223) & -40.26 & 47.58 & 7.12 & 14.98 & -17.20 & 14.59 & 0.23 & 5.52 \\
\hline & B11(182) & -25.49 & 48.94 & 11.09 & 16.84 & -16.05 & 18.38 & 1.50 & 5.57 \\
\hline & B12(1275) & -36.24 & 62.98 & 7.55 & 15.59 & -30.84 & 21.98 & -4.63 & 8.60 \\
\hline & B13(22) & -58.70 & 27.39 & 8.54 & 19.84 & -39.70 & 16.22 & -0.55 & 10.17 \\
\hline \multirow{3}{*}{$\mathrm{C}$} & C1(933) & -51.82 & 165.72 & 4.32 & 20.46 & -28.65 & 28.86 & -2.91 & 8.05 \\
\hline & $\mathrm{C} 2(355)$ & -102.99 & 26.22 & -27.20 & 34.32 & -28.58 & 29.03 & 2.00 & 10.09 \\
\hline & C3(47) & -34.81 & 42.06 & 10.89 & 17.94 & -18.80 & 17.40 & -3.34 & 8.57 \\
\hline $\mathrm{D}$ & $\mathrm{D}(1397)$ & -76.01 & 80.74 & 2.58 & 15.80 & -56.26 & 60.55 & -2.43 & 9.70 \\
\hline $\mathrm{E}$ & $\mathrm{E}(56)$ & -9.07 & 34.98 & 14.75 & 19.12 & -32.14 & 29.89 & 6.63 & 24.84 \\
\hline $\mathrm{F}$ & $\mathrm{F}(21)$ & -14.91 & 21.65 & 1.22 & 7.65 & -33.91 & -6.68 & -21.58 & 22.56 \\
\hline $\begin{array}{l}\text { Whole } \\
\text { area }\end{array}$ & 8242 & -102.99 & 165.72 & 4.08 & 18.56 & -80.05 & 60.55 & -0.84 & 10.39 \\
\hline
\end{tabular}

\subsubsection{The effects of topographic variables (elevation, slope and aspect) on the accuracy of DEMs}

Some previous studies have demonstrated that topographic characteristics, such as elevation, slope and aspect, affect the accuracy of DEMs [14, 29 and 30]. However, our study doesn't show clear relationship between elevation differences and elevation (Fig. 3), indicating that elevation has little effect on vertical accuracy in the TP. This result is consistent with the ASTER GDEM validation report (2009) and the findings of Gorokhovich and Voustianiouk (2006) concerning SRTM.

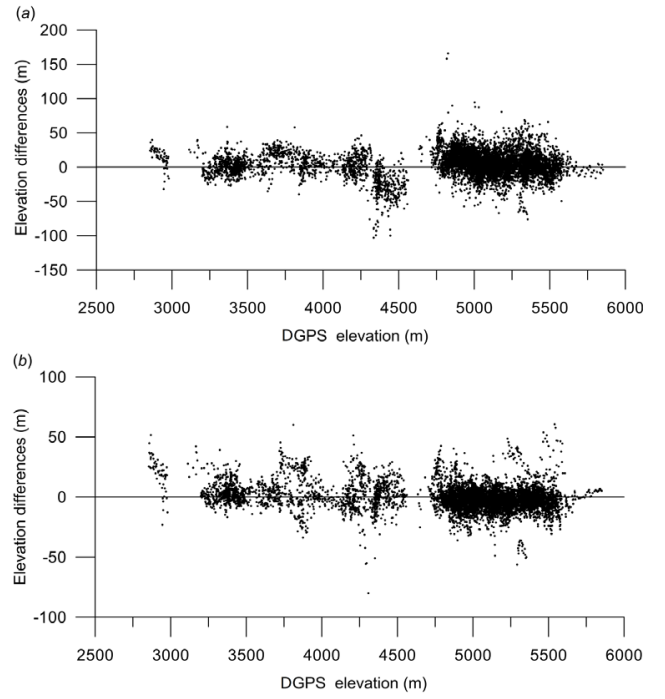

Fig. 3. Plots of vertical differences between the DEMs and DGPS versus elevations from DGPS: (a) GDEM minus DGPS; (b) SRTM3 minus DGPS.

The statistical differences of the elevation differences for different surface slope classes highlight that surface slope is an important factor affecting the vertical accuracy of the DEMs (Table 3). Generally, RMSR and 
MAD of the elevation differences for both DEMs increase with slope steepness, indicating that the vertical error of the DEMs increases with slope steepness, and is less significant in SRTM3 than in GDEM. This result is consistent with that obtained by Racoviteanu et al. (2007) and Gao et al. (2019) [29, 17]. All GDEM mean vertical errors are above zero, while most of the SRTM3 mean vertical errors are below zero. Thus suggests that the elevations obtained from GDEM are generally higher, while elevations obtained from SRTM3 are lower than DGPS measurements (Table 3). It's also noted that both RMSE and MAD are much larger for GDEM than for SRTM3, meaning smaller deviations of SRTM3 from DGPS than GDEM for all slope classes.

Table 3. Statistical results of elevation differences for different slope classes.

\begin{tabular}{|c|c|c|c|c|c|c|c|}
\hline \multirow{2}{*}{\begin{tabular}{|l} 
Slope \\
(degree)
\end{tabular}} & \multirow[t]{2}{*}{ Count } & \multicolumn{3}{|c|}{ ASTER GDEM - DGPS(m) } & \multicolumn{3}{|c|}{ SRTM3 - DGPS(m) } \\
\hline & & Mean & RMSE & MAD & Mean & RMSE & MAD \\
\hline$\leq 2$ & 639 & 3.51 & 15.85 & 11.47 & -2.12 & 6.87 & 4.49 \\
\hline $2 \sim 5$ & 1834 & 4.30 & 16.15 & 12.17 & -1.41 & 9.29 & 6.16 \\
\hline $5 \sim 10$ & 2847 & 4.64 & 17.67 & 13.44 & -0.32 & 10.93 & 7.83 \\
\hline $10 \sim 15$ & 1690 & 3.78 & 19.57 & 15.08 & 0.14 & 11.44 & 8.31 \\
\hline $15 \sim 20$ & 779 & 2.60 & 22.01 & 16.25 & -0.59 & 10.63 & 7.90 \\
\hline $20 \sim 25$ & 363 & 3.68 & 24.24 & 19.53 & -3.53 & 10.95 & 8.54 \\
\hline $25 \sim 30$ & 76 & 4.44 & 29.38 & 23.69 & -6.36 & 9.58 & 7.91 \\
\hline$>30$ & 14 & 13.90 & 25.70 & 20.49 & -4.53 & 9.58 & 7.51 \\
\hline
\end{tabular}

Surface aspect is also an important factor controlling the vertical accuracy of the DEMs, as shown in Fig. 4. The RMSE of GDEM minus DGPS is smaller for N-S facing aspects and greater for those facing NW-SE. It ranges from $16.47 \mathrm{~m}$ on $\mathrm{N}$-facing aspects to $19.82 \mathrm{~m}$ on those facing NE (Fig. 4(a)); these RMSE values are greater than those for SRTM3, which range from $8.87 \mathrm{~m}$ on $\mathrm{W}$-facing aspects to $12.20 \mathrm{~m}$ on those facing SE (Fig. 4(b)). The RMSE of the SRTM3 tends to be greater in aspects of N, NE, E and SE, and smaller in aspects of $\mathrm{NW}, \mathrm{W}, \mathrm{SW}$ and $\mathrm{S}$. This is probably related to the flight direction of the shuttle radar. The orbital inclination of the space shuttle is $57^{\circ}$ [31]. Radar shadows are formed on the back slope of the mountain. There is no radar echo signal in the shadow area, which seriously affects the quality of DEM acquisition by interferometric radar [32], thus the RMSE of the SRTM3 are directional. (a)

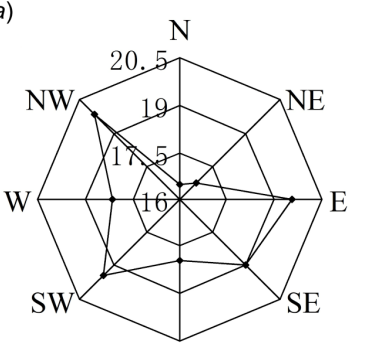

$\mathrm{S}$ (b)

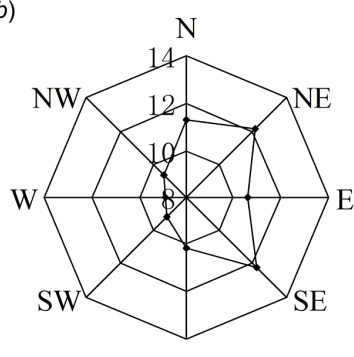

$\mathrm{S}$
Fig. 4. RMSE changes with aspects for GDEM minus DGPS (a), SRTM3 minus DGPS (b)

\subsubsection{Assessment of DEM vertical accuracy in a glacial area}

Both DEMs of Yangbajing were used to evaluate the vertical accuracy of the DEMs in glacial area by comparing to DGPS measurements of a glacier surface (Fig. 5). The range of GDEM errors is $-16.34 \mathrm{~m}-22.65 \mathrm{~m}$, with a mean error of $-1.43 \mathrm{~m}$, and a RMSE of $8.55 \mathrm{~m}$. The range of SRTM3 errors is $-16.42 \mathrm{~m}-6.74 \mathrm{~m}$, with a mean error of $-1.39 \mathrm{~m}$, and a RMSE of $5.87 \mathrm{~m}$. Both DEMs are within the officially-stated accuracy range, and vertical accuracy is better for SRTM3 than for GDEM.

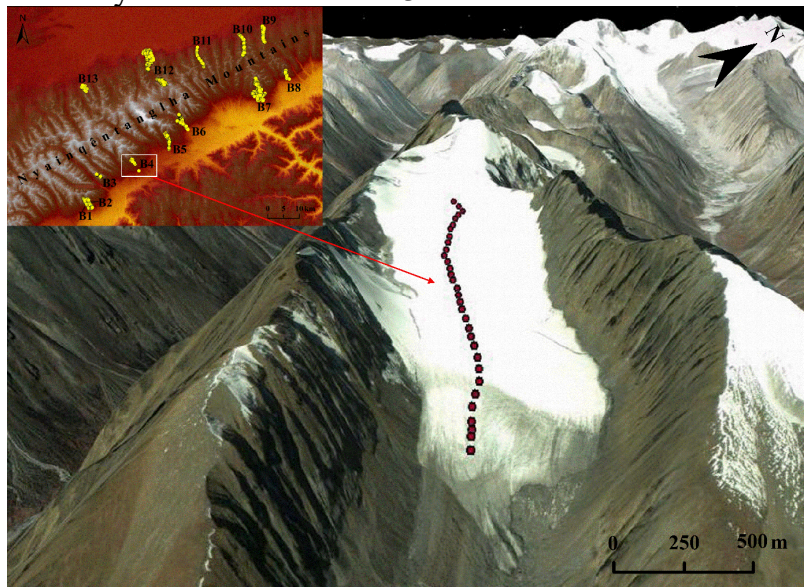

Fig. 5. DGPS measurement points on the glacier surface at Yangbajing, west of the Naiyqentanggula Mountains.

Elevations in SRTM3 tend to be lower than those in DGPS. This is probably due to the C-band of SRTM's penetration capability into the glacier [33]. Height differences between SRTM3 and DGPS tend to increase with elevation (Fig. 6), indicating that SRTM3 errors increase with elevation in glacial area.

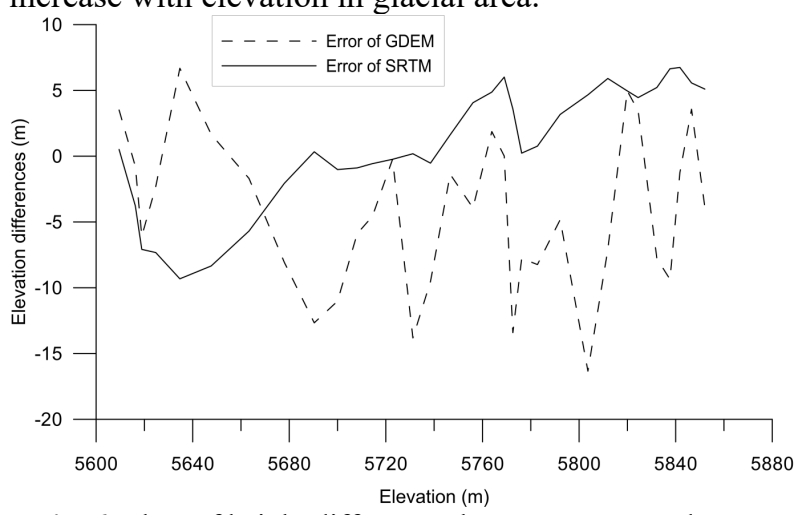

Fig. 6. Plots of height differences between DEM and DGPS point elevations in a glacier area (the solid line stands for SRTM and the dashed line for the ASTER GDEM).

\subsubsection{Assessment of DEM vertical accuracy for Laolongwan}

In order to evaluate the vertical accuracy for different types of landform, the data from Laolongwan Valley were selected for analysis (Fig. 7). Table 4 shows that the accuracy of SRTM3 is higher than GDEM when presenting the actual elevations of mountain ridges and valleys, differing from the results obtained by Hayakawa (2008) [6]. 


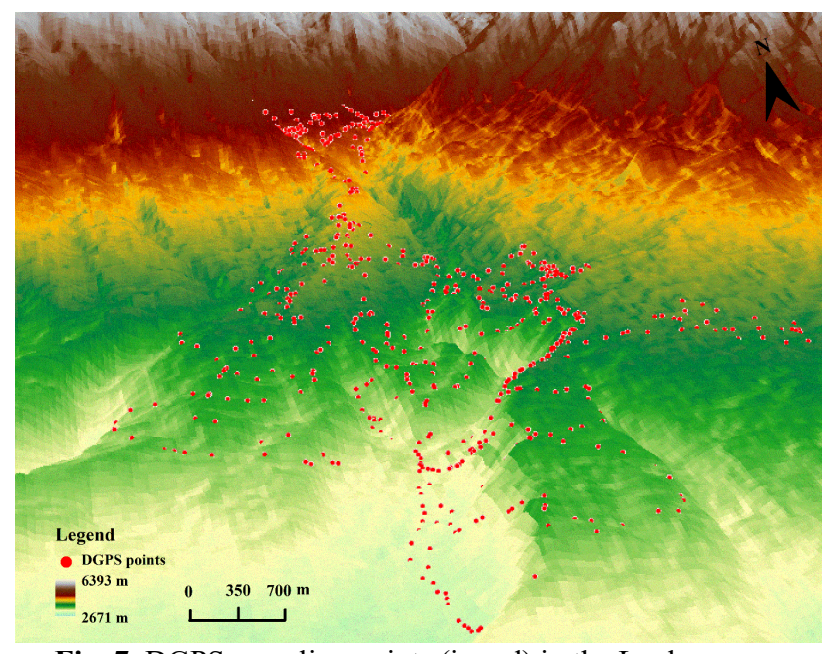

Fig. 7. DGPS sampling points (in red) in the Laolongwan Valley, east of the Qilianshan Mountains.
Considering all the samples from Laolongwan, GDEM displays better elevation accuracy on mountain ridges but poorer elevation accuracy in mountain valleys, while SRTM3 presents elevation poorly for both mountain ridges and valleys. These contrasts probably result from mountains blocking the satellite signals in valleys, and, as SRTM3 has a larger raster size, the elevation changes on mountain ridges are obscured. The vertical errors produced by GDEM and SRTM3 increase with slope, which is consistent with the results we obtained in all the study regions.

Table 4. Statistical results of elevation differences of different landforms in the Laolongwan Valley.

\begin{tabular}{|c|c|c|c|c|c|c|c|c|}
\hline \multirow{2}{*}{$\begin{array}{l}\text { landform } \\
\text { types(Count of } \\
\text { samples) }\end{array}$} & \multicolumn{4}{|c|}{ ASTER GDEM - DGPS(m) } & \multicolumn{4}{|c|}{ SRTM3 - DGPS(m) } \\
\hline & Min & $\operatorname{Max}$ & Mean & RMSR & Min. & $\operatorname{Max}$ & Mean & RMSR \\
\hline $\begin{array}{l}\text { mountain } \\
\text { ridges( } 37)\end{array}$ & -10.50 & 33.68 & 3.70 & 10.03 & -0.50 & 19.92 & 7.81 & 9.47 \\
\hline $\begin{array}{l}\text { mountain } \\
\text { valleys(34) }\end{array}$ & -35.14 & 37.11 & -2.27 & 16.18 & -26.46 & 11.12 & -3.48 & 8.44 \\
\hline plain zone(21) & -31.06 & 27.56 & -0.45 & 10.71 & -7.70 & 13.86 & 1.87 & 4.98 \\
\hline $\begin{array}{l}\text { gentle slope } \\
\text { area(268) }\end{array}$ & -35.14 & 37.25 & 3.14 & 12.41 & -26.40 & 21.52 & 2.06 & 7.34 \\
\hline $\begin{array}{l}\text { steep slope } \\
\text { area }(90)\end{array}$ & -21.43 & 58.76 & 6.26 & 16.49 & -19.21 & 26.76 & 2.78 & 9.20 \\
\hline all samples(379) & -35.14 & 58.76 & 3.61 & 13.37 & -26.46 & 26.76 & 2.20 & 7.43 \\
\hline
\end{tabular}

It is common to use DGPS measurements to assess the accuracy of remote sensing-derived DEMS (RSDEMs). However, an elevation value for RS-DEMs is only an average value of true elevations that fall within each pixel [34, 35], whereas a DGPS elevation value is simply a value in a point. This means we compare a very local elevation value with a value that represents the average elevation within a larger area. Any assessment of the vertical accuracy of RS-DEMs thus presents only an average vertical accuracy at the DGPS point, reflecting the macroscopic accuracy of RS-DEMs. Theoretically, the uncertainty of an elevation value of a point obtained from SRTM3 is higher than that from GDEM, considering the coarser resolution of SRTM3 than GDEM. However, the statistical results in this study suggest that SRTM3 has a higher accuracy than GDEM in the region of TP, assuming that the DGPS measurements represent the true elevations.

\subsection{Assessment of topographic information}

\subsubsection{Visual comparisons}

Fig. 8 illustrates the visual effect produced by the three DEMs. GDEM reflects the rough surface of the terrain, there are many small fluctuations which reflect the detailed information of the terrain. Compared with GDEM, DEM10 also clearly shows the main terrain characteristics, but it is not smooth and with some contour texture.DEM10 is derived from topographic map and some information on the ground is ignored in the process of generating DEM. SRTM3 looks vague and does not reflect detailed terrain information. SRTM3 loses some terrain details because it is resampled to $90 \mathrm{~m}$ from SRTM1 (30m).Comparing the three DEMs, GDEM shows visual effects than other two DEMs, and DEM10 performances better than SRTM3.

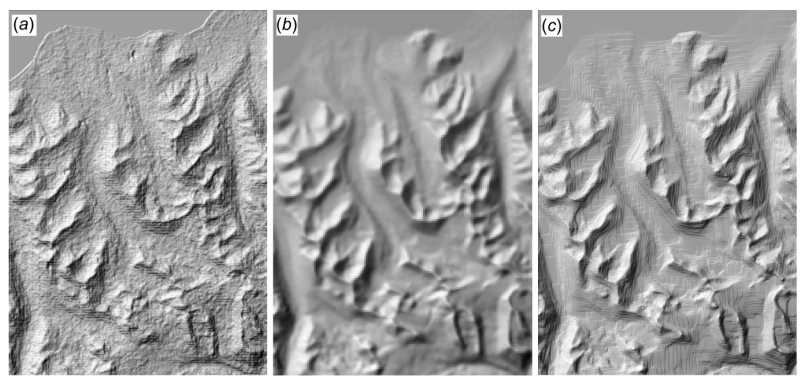

Fig. 8. Shaded relief images of the three DEMs: (a) GDEM; (b) SRTM3; (c) DEM10. 


\subsubsection{Slope analysis}

In accordance with the result obtained by other studies[28,36], Table 5 shows that GDEM has the steepest mean slope $\left(15.85^{\circ}\right)$ and dem 10 and SRTM3 have similar mean slopes, which are $13.93^{\circ}$ and $13.46^{\circ}$, respectively, indicating that DEMs with a higher resolution generally present greater apparent gradients. Steep slopes $\left(>15^{\circ}\right)$ are more common in GDEM, whereas gentle slopes $\left(0^{\circ} \sim 9^{\circ}\right)$ are more frequent in DEM10 and SRTM3, implying that, compared to DEM10 and SRTM3, GDEM could better represent the topographic characteristics of the mountainous region with high relief. SRTM3 has the highest proportion in the slope range of $3^{\circ} \sim 9^{\circ}$. DEM10 has higher proportions than SRTM3 in the other two slope ranges $\left(<3^{\circ}\right.$ and $\geqslant$ $25^{\circ}$ ), thus the slope of SRTM3 tend to be more median than that in DEM10. A possible reason is that SRTM3 loses some terrain details (too steep or too flat terrain information) when resampled to $90 \mathrm{~m}$ from SRTM1 $(30 \mathrm{~m})$.

Table 5. Slope parameters in different slope levels of three DEMs.

\begin{tabular}{|c|c|c|c|c|c|c|}
\hline \multirow{2}{*}{$\begin{array}{c}\text { DEM } \\
\text { type }\end{array}$} & \multicolumn{5}{|c|}{ Distribution frequencies (\%) } & \multirow{2}{*}{$\begin{array}{c}\text { Mean } \\
\text { slope }\end{array}$} \\
\cline { 2 - 7 } & $<3^{\circ}$ & $3 \sim 9^{\circ}$ & $9 \sim 15^{\circ}$ & $15 \sim 25^{\circ}$ & $\geq 25^{\circ}$ & \\
\hline $\begin{array}{c}\text { ASTER } \\
\text { GDEM }\end{array}$ & 10.24 & 22.78 & 21.55 & 24.08 & 21.54 & $15.85^{\circ}$ \\
\hline DEM10 & 22.18 & 22.04 & 14.7 & 21.61 & 19.47 & $13.93^{\circ}$ \\
\hline SRTM3 & 14.79 & 27.22 & 19.33 & 22.23 & 16.42 & $13.46^{\circ}$ \\
\hline
\end{tabular}

In conclusion, form visual comparisons and slope analysis, GDEM could better reflect the details information topographic characteristics than DEM10 and SRTM3 and DEM10 perform better that SRTM3, which is in accordance with the result obtained by other studies $[28,36]$ that DEMs with a higher resolution generally reflect more detailed local terrain changes than those with a lower resolution.

The detailed topographic information reflected by three DEMs is related to the way of data generation. GDEM is an automatic generation of satellite images with a resolution of 15 meters, in which more original satellite image information is retained [26]; DEM10 is generated from digitized 1:100,000 topographic maps produced from aerial photographs. This process generating topographic map from aerial photo called cartographic generalization could lose a lot of detailed information and obscure presentation of local topographic fluctuations. SRTM data is derived from Radar image with data points posted every 1 arc-second, approximately 30 meters. When SRTM3 was resampled from SRTM1 [24], detailed topographic information could have been largely ignored.

\section{Conclusion}

Our assessment demonstrates that both ASTER GDEM (mean RMSE 18.6m) and SRTM3 (mean RMSE 10.4m) lie within their vertical nominal accuracies of $20 \mathrm{~m}$ and $16 \mathrm{~m}$, respectively. The vertical accuracy of DEMs decreases with terrain slope and varies in aspect, but does not respond to elevation change. In general, SRTM3 has higher accuracies than ASTER GDEM in the TP, while the latter is more accurate for mountain ridges than valleys and the accuracy of SRTM3 is poor for both mountain ridges and valleys. In glacial areas, the RMSE of ASTER GDEM and SRTM3 are $8.55 \mathrm{~m}$ and $5.87 \mathrm{~m}$, respectively. Elevation values tend to be higher for ASTER GDEM and lower for SRTM3 compared to those derived from DGPS. In the aspect of topographic information, the performance of ASTER GDEM is the best, followed by DEM generated from $1: 100,000$ topographic map and SRTM3 is the last.

\section{Acknowledgements}

This research was supported by the National Natural Science Foundation of China (Grant nos. 41501067, 41230523) and Comprehensive surveys of natural resources and environment in typical spatial-planning areas of China (DD20190506). We would like to thank Professor Lide Tian for providing DGPS point data for glacial areas and Professor Shifeng Wang for providing DGPS data for the Gila area.

\section{References}

1. Rossetti, D. F.,Márcio M. Valeriano (2007) Evolution of the lowest amazon basin modeled from the integration of geological and srtm topographic data. CATENA,70(2), 0-265.

2. Bailey, J. E. , Self, S. , Wooller, L. K. , \& MouginisMark, P. J. (2007) Discrimination of fluvial and eolian features on large ignimbrite sheets around la pacana caldera, chile, using landsat and srtm-derived dem. Remote Sensing of Environment, 108(1), 2441.

3. Schumann, G., Matgen, P., Cutler, M. E. J., Black, A., Hoffmann, L., Pfister, L. (2008) Comparison of remotely sensed water stages from lidar, topographic contours and srtm. ISPRS Journal of Photogrammetry and Remote Sensing, 63(3), 283296.

4. Bolch, T., Yao, T., Kang, S., Buchroithner, M. F., Scherer, D., Maussion, F., Huintjes, E., and Schneider, C. (2010) A glacier inventory for the western Nyainqentanglha Range and the Nam Co Basin, Tibet, and glacier changes 1976-2009, The Cryosphere, 4, 419-433.

5. Rodriguez, E., Morris, C.S., and Belz, J.E. (2006) A global assessment of the SRTM performance. Photogrammetric Engineering and Remote Sensing, 72(3), 249-260. 
6. Hayakawa, Y. S., Oguchi, T., \& Lin, Z., (2008) Comparison of new and existing global digital elevation models: aster g-dem and srtm-3. Geophysical Research Letters, 35(17), L17404

7. Hirt, C., Filmer, M. S., \& Featherstone, W. E. (2010) Comparison and validation of the recent freely available aster-gdem ver1, srtm ver4.1 and geodata dem-9s ver3 digital elevation models over australia. Australian Journal of Earth Sciences, 57(3), 337-347.

8. Zhan, L., Tang, G.-a., and Yang, X. (2010) Evaluation of SRTM DEMs Elevation Accuracy: A Case Study in Shaanxi Province, Geography and Geo-Information Science, 26(1), 34-36.

9. Hengl, T., Reuter, H. (2011) How accurate and usable is gdem? a statistical assessment of gdem using lidar data, Geomorphometry. (http://geomorphometry.org/HenglReuter2011, accessed on 2011-02-25)

10. Huang, X., Xie, H., Liang, T., \& Yi, D. (2011) Estimating vertical error of srtm and map-based dems using icesat altimetry data in the eastern tibetan plateau. INTERNATIONAL JOURNAL OF REMOTE SENSING, 32(18), 5177-5196.

11. Hvidegaard, S. M., Sandberg S, Rensen, L., Forsberg, René (2012) Aster gdem validation using lidar data over coastal regions of Greenland. Remote Sensing Letters, 3(1), 85-91.

12. Zhao, S., Cheng, W., Zhou, C., Chen, X., Zhang, S., \& Zhou, Z., et al. (2011) Accuracy assessment of the aster gdem and srtm 3 dem: an example in the loess plateau and north china plain of china, International Journal of Remote Sensing, 32(23), 8081-8093.

13. Wang, W., Yang, X., and Yao, T. (2012) Evaluation of aster gdem and srtm and their suitability in hydraulic modelling of a glacial lake outburst flood in southeast tibet. Hydrological Processes, 26(2), 213-225.

14. Gorokhovich, Y., Voustianiouk, A. (2006) Accuracy assessment of the processed srtm-based elevation data by cgiar using field data from usa and thailand and its relation to the terrain characteristics. Remote Sensing of Environment, 104(4), 409-415.

15. Antonios Mouratidis, PierreBriole, KostasKatsambalos, Srtm 3"dem (versions 1, 2, 3, 4) validation by means of extensive kinematic gps measurements: a case study from north Greece. International Journal of Remote Sensing. 2010, 31(23).

16. DU Xiao-ping, GUO Hua-dong, FAN Xiang-tao, et al., Vertical Accuracy Assessment of SRTM and ASTER GDEM over Typical Regions of China Using ICESat/GLAS. Earth Science-Journal of China University of Geosciences. 2013, 38(4):887897.

17. Gao Zhiyuan, Xie Yuanli1, Wang Ninglian, et al. (2019) Response of Three Global DEM Data Accuracy to Different Terrain Factors in QinghaiTibet Plateau, 39(2):184-191.
18. Wang, Y., Chen, X., Bo, Y., and Li, X. (2010) Monitoring glacier volume change based on multisource DEM and multi-temporal remote sensing images - a case study in the mount Naimona'nyi region on the TP. J. Glaciol. Geocryol, 32(1), 126132.

19. Tian, B., Wang, L., \& Koike, K. (2011) Spatial statistics of surface roughness change derived from multi-scale digital elevation models. Procedia Environmental Sciences, 7, 0-257.

20. Gao, T., Kang, S., Krause, P., Cuo, L., \& Nepal, S. (2012) A test of j2000 model in a glacierized catchment in the central tibetan plateau. Environmental Earth Sciences, 65(6), 1651-1659.

21. Fu, P., Heyman, J., H?Ttestrand, C. , Stroeven, A. P. , \& Harbor, J. M. (2012) Glacial geomorphology of the shaluli shan area, southeastern tibetan plateau. Journal of Maps, 8(1), 48-55.

22. WAN Jie, LIAO Jingjuan, XU Tao, et al. (2015) Accuracy evaluation of SRTM data based on ICESat/GLAS altimeter data: A case study in the Tibetan Plateau. REMOTE SENSING FOR LAND \& RESOURCES, 27(1): 100-105.

23. Farr, T.G., Paul, A.R., Edward, C., Robert, C., Riley, D., Scott, H., Michael, K.,Mimi, P., Ernesto, R., Ladislav, R., David, S., Scott, S., Joanne, S., Jeffrey, U.,Marian, W., Michael, O., Douglas, B. and Douglas, A. (2007) The shuttle radartopography mission. Reviews of Geophysics, 45, RG2004.

24. Rabus, B., Eineder, M., Roth, A., Bamler, R. (2013) The shuttle radar topography mission - a new class of digital elevation models acquired by spaceborne radar. ISPRS Journal of Photogrammetry and Remote Sensing, 57(4), 241-262.

25. Smith and Bridget (2003) Accuracy and resolution of shuttle radar topography mission data. Geophysical Research Letters, 30(9), 1467.

26. Aster (2009) ASTER Global DEM Validation Summary Report (Prepared by ASTER GDEM METI/ERSDAC NASA/LPDAAC USGS/EROS), (June 2009), 28.

27. Hai-Rong, G., Wen-Hai, J., Yuan-Xi, Y. (2004) The systematic difference and its distribution between the 1985 national height datum and the global quasigeoid. Acta Geodaetica Et Cartographic Sinica.

28. Deng, Y., Wilson, J. P., \& Bauer, B. O. (2007) Dem resolution dependencies of terrain attributes across a landscape. International Journal of Geographical Information Systems, 21(2), 27.

29. Racoviteanu, A. E., Manley, W. F., Arnaud, Y., \& Williams, M. W. (2007) Evaluating digital elevation models for glaciologic applications: an example from nevado coropuna, peruvian andes. Global and Planetary Change, 59(1-4), 0-125.

30. Tachikawa, T., Kaku, M., Iwasaki, A., Gesch, D., Oimoen, M., \& Zhang, Z., et al. (2011) Aster global digital elevation model version 2-summary of validation results. Kim Fakultas Sastra Dan Budaya. 
31. Huadong Guo, Yun Shao, ChangLin Wang, et al. (2000) Theories and Application of Radar for Earth Observation. Science Press, Beijing, China.

32. Eineder, M., \& Holzner, Jürgen (200) Interferometric DEMs in Alpine Terrain - Limits and Options for ERS and SRTM. IEEE International Geoscience \& Remote Sensing Symposium, IEEE.

33. Rignot, E., Echelmeyer, K., \& Krabill, W. (2001) Penetration depth of interferometric synthetic-aperture radar signals in snow and ice. Geophysical Research Letters, 28(18).

34. Grohmann, C. H., \& Steiner, S. S. (2006) Srtm resample with short distance-low nugget kriging. International Journal of Geographical Information Science, 22(8), 895-906.

35. Reuter, H. I., Nelson, A., Strobl, P., Mehl, W., \& Jarvis, A. (2010) A first assessment of Aster GDEM tiles for absolute accuracy, relative accuracy and terrain parameters. Geoscience \& Remote Sensing Symposium. IEEE, 240-243.

36. Yan-Chao Y., Shu-Wen Z., Shu-Ping Y. (2008) Evaluation of srtm data quality in area of undulating hills of northeast china, Journal of the Graduate School of the Chinese Academy of Sciences, 25(1), 41-46. 